\title{
AC 2007-1185: PROMOTING UNDERGRADUATE RESEARCH BY CREATING A RESEARCH OPTION IN A TECHNICAL COMMUNICATION COURSE
}

\section{Jenny Lo, Virginia Tech}

JENNY LO, assistant professor in the Department of Engineering Education at Virginia Tech, is interested in engineering ethics, curriculum design, issues related to engineering freshmen, and undergraduate research.

\section{Lisa McNair, Virginia Tech}

LISA MCNAIR, assistant professor in the Department of Engineering Education at Virginia Tech, is interested in qualitative methods, interdisciplinary learning and collaboration, strategies for improving professional skills of engineering students, and risk communication.

\section{Whitney Edmister, Virginia Tech}

WHITNEY EDMISTER, Assistant Director of the Center for the Enhancement of Engineering Diversity at Virginia Tech, is interested in issues related to diversity, promoting undergraduate research, and retention.

\section{Michael Alley, Pennsylvania State University}

MICHAEL ALLEY, associate professor of Engineering Communication at Penn State, has been active in research related to the promotion of undergraduate research and the design of presentation slides for more effective student learning. 


\title{
Promoting Undergraduate Research by Creating a Research Option in a Technical Communication Course*
}

\begin{abstract}
Although many institutions have called for more undergraduate research, incorporating significant research experiences into undergraduate engineering curricula has proven to be challenging. This paper presents the results of a two-year experiment in the College of Engineering at Virginia Tech to address this problem by means of a research option in the traditional technical communication course, which is a required course in many engineering curricula. In this research option, students had the opportunity to prepare for and to document a summer research experience. To that end, the research option of the course was divided into two segments: (1) a spring segment to prepare students for a summer research experience, and (2) a fall segment to teach students how to document that research experience. This research option culminated with the students participating in an undergraduate research symposium that showed other undergraduates the benefits of and the opportunities for research experiences.

The main results of the experiment have been positive. First, the course has been able to attract students who are academically strong and capable of succeeding in graduate school. For the two years, the average GPA of the students has been 3.7. Second, the course has been able to attract a significant number of students from underrepresented groups. Over the two years of the experiment, the course has had almost a 50 percent enrollment from students in groups underrepresented in engineering. Third, almost all of the students have been able to find funded research opportunities for the summer. This result addresses what was perhaps the biggest question mark of the experiment. Fourth, the students have learned much about technical communication, as evidenced by the relatively high number of publications at professional conferences and in professional journals that several students in the course have either authored or co-authored.

A continuing challenge for the course sequence has been the integration of this unconventional course sequence into different engineering curricula. For instance, one department has been reluctant to accept this course sequence as a substitute for the traditional technical communication course. In other cases, students have taken the sequence even though the credit hours do not contribute to their plan of study. A second concern for the course has been the attrition between the spring course and the fall course. More than one-third of the students have opted not to take second portion of the course, but most of these have been students who do not need the course credits to graduate.
\end{abstract}

Although more time is needed to assess the effect of this course's research experiences on the careers of these students, the course sequence appears to be a success. The next step is to try this experiment on different campuses, especially those in which technical communication is integrated differently into engineering curricula. Next year, for example, a modified version of the course sequence will be taught through the English Department at Penn State.

\footnotetext{
* This work is supported by the National Science Foundation: NSF Project 0341171.
} 


\section{Introduction}

The Boyer Commission Report has urged universities to "make research-based learning the standard" for the education of undergraduates. ${ }^{1}$ Also calling for more research by undergraduates in science, technology, engineering and mathematics are the National Science Foundation, ${ }^{2}$ the American Association for the Advancement of Science, ${ }^{3}$ and the National Research Council. ${ }^{4}$ Participation in research not only deepens a student's understanding in science, mathematics, engineering, and technology, but also promotes communication and teamwork to solve complex problems. ${ }^{5}$

As stated by the Reinvention Center at Stony Brook, "When undergraduates working alongside faculty participate in the generation of knowledge or artistic creation, they join the university's rich intellectual community and they derive unique, life-long benefits." In addition, liberal arts colleges claim that the reason that they send so many of their undergraduates to graduate school is because so many of their students participate in undergraduate research. ${ }^{22}$ For these reasons, engaging more engineering undergraduates in research is a goal of many engineering colleges. However, given the pressures to maintain a low number of credit hours in engineering curricula, engineering departments are hard pressed to incorporate courses that teach best research practices and engage students in meaningful research.

One opportunity that exists is the three-credit technical communication course required by many engineering curricula. According to a survey of the 73 top ranked engineering colleges in the United States and Canada, ${ }^{7} 50 \%$ of the U.S. schools and $80 \%$ of the Canadian schools require a course in technical communication. Certainly one variable in these courses is who teaches them. For instance, the course is taught as a departmental course housed within engineering departments such as at the University of Texas, ${ }^{8}$ as a college course housed in the College of Engineering such as at the University of Wisconsin, ${ }^{9}$ and most often as a university course housed in the English Department such as at Clemson. ${ }^{10}$

Despite these administrative differences, the objectives and strategies of the different courses are strikingly similar. For instance, the courses typically require students to perform library research that serves as the content for the main assignments: proposal, formal presentation, and formal document. Given that this required course already provides the foundation for a significant research experience, the question arises whether a special option within this course could be created that complements the course's library research component with experimental, computational, or theoretical research in actual laboratories. The benefits would be not only that the students would gain valuable research experiences, but also that the students' appreciation for the communication would deepen, because the students would be more likely to attain deeper understanding and to assume more ownership of the content.

One strategy for this research option would be as a frame for a summer research experience, such as a Research Experience for Undergraduate (REU) sponsored by the National Science Foundation. ${ }^{11}$ This framing would entail preparing the students during the spring for the summer research experiences and then allowing students enough time to document the experiences in the fall. Such was the strategy for the course option that we adopted at Virginia Tech and that we have assessed in this paper.

Our three-credit research option was to serve as a substitute for the three-credit technical writing course required by four engineering departments in the College of Engineering. The 
spring segment that prepared the students for the research experiment was one credit hour, and the fall segment that had students document the research experience was two credit hours.

Presented in this paper is a detailed description of the research course option. Following that are the complete results for the 2005 calendar year and partial results for the 2006 calendar year: (1) recruiting of undergraduates for the pilot offering of the research option, (2) the onecredit spring segment to prepare students for the summer research experience, (3) the summer research experiences, and (4) the two-credit fall segment that taught students how to communicate those experiences. Following that is a discussion of the challenges that this strategy poses.

\section{Description of Tested Course}

Spanning two semesters and framing a summer research experience, our research option for a technical communication course was designed both to attract undergraduates to pursue research experiences and to enrich those experiences for the participating undergraduates. As shown in Figure 1, the first part of the course, which was taught in the spring before the summer research experience, was to prepare undergraduates for that research experience by having them apply to funded research positions, learn about best research practices, and perform a literature review of their intended research topic. The second part of the course, which was taught in the fall following the summer research experience, was to give students the time and instruction needed to communicate their summer research. During the fall course, the students participated in an open symposium. One of the purposes of the symposium was to attract other undergraduates into pursuing research experiences. For that reason, freshmen, sophomores, and juniors in engineering were encouraged to attend the symposium.

The College of Engineering at Virginia Tech, which was the testing site for this course, was an appropriate choice for several reasons. The College has a large and diverse undergraduate engineering population from which to draw students, the College has many respected laboratories in which undergraduates could perform research, and the College has the Center for Enhancement of Engineering Diversity that is committed to helping undergraduates, especially those in underrepresented groups, ${ }^{12}$ obtain research experiences. In addition, the College is recognized nationally for its initiatives in technical communication. For instance, the College hosts the Writing Guidelines for Engineering and Science Students, ${ }^{13}$ which is the first Google listing for the term engineering writing, and has recently chartered the college-wide Engineering Communication Center (VTECC).

Designed to have no more than 25 undergraduates, which is a typical limit for technical communication courses, this course sequence was tested to answer the following four questions:

(1) How readily would undergraduates, particularly undergraduates from underrepresented groups in engineering, enroll for such a course?

(2) For such a course, what percentage of students in the course would be able to find summer research positions?

(3) Would the spring and fall segments of the course significantly enrich the summer research experience?

(4) Would students in this course sequence develop their technical communication skills as well as students do in a traditional technical communication course? 
The first question was addressed by the interest shown in the course by undergraduate engineers. Also considered was the diversity and academic standing of those students. The second question was answered by examining how many students from the pilot course obtained offers for funded research positions. To address the third question, we surveyed students immediately after their summer experience and at the end of the fall semester portion of the course.

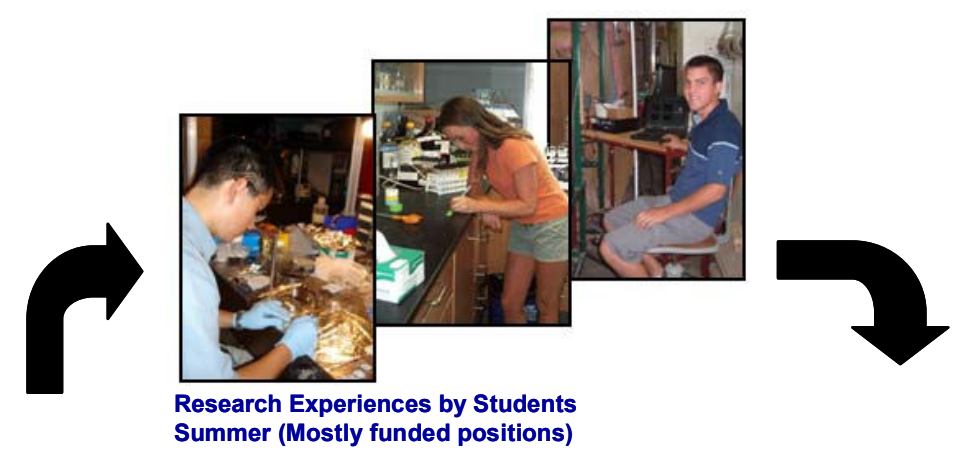

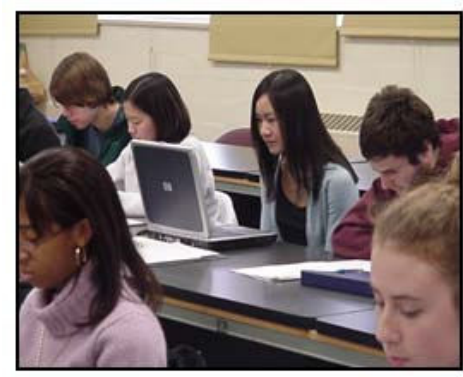

Preparing for Research Spring (1 credit)

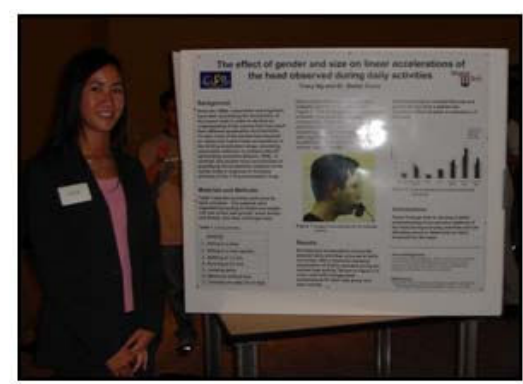

Documenting Research Fall (2 credits)
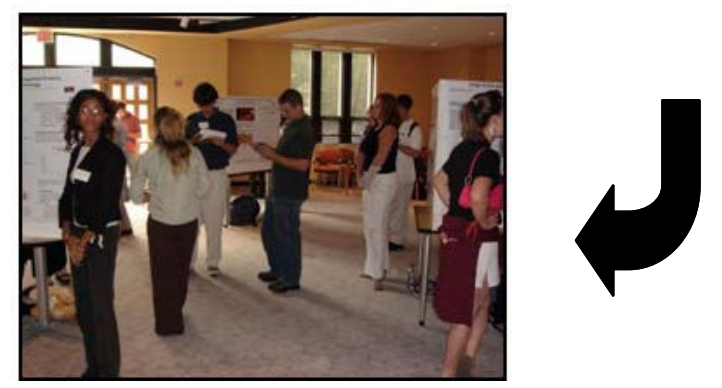

Undergraduate Research Symposium Fall (Recruitment tool for next sequence)

Figure 1. Relation of proposed technical communication course sequence to summer research experience. $^{14}$

The final question was assessed in three different ways. The first was a self-assessment by the students. The second was a tracking of whether students were able to publish any of their work in the professional conferences and publications of their disciplines. The third was an assessment of the writings and presentations of these students by the course's two writing instructors. In our study, one instructor taught the Fall course segment in 2005, and the other 
taught the Fall segment in 2006. Combined, these two instructors have taught a traditional technical communication course to more than 1500 students at six other universities: Georgia Tech, San Jose State University, the University of Alabama, the University of Maryland, the University of Texas at Austin, and the University of Wisconsin-Madison.

\section{Results}

Recruitment of Students. For the pilot course sequence in calendar year 2005, recruitment began in Fall 2004. This recruitment consisted of three efforts. The first was emailing announcements of the option to those students who would be eligible. In general, eligibility meant having a GPA above 3.5 , which is the level that many national laboratories require for acceptance into their summer research programs. These emails were sent out just prior to the registration period for the Spring 2005 semester, in which the sequence for the research option was to begin.

Second, an information session was held in the College on undergraduate research. This session informed undergraduates, particularly sophomores and juniors, about the benefits and opportunities for undergraduate research on Virginia Tech's campus, at other engineering colleges, and at the national laboratories. In addition, the research-course sequence was discussed as a means to help obtain and deepen such a research experience.

Third, we advertised, collected abstracts for, and held a pilot symposium on undergraduate research in the College of Engineering. The purpose of this symposium was twofold: (1) to attract qualified undergraduates to the pilot research-course sequence that we were going to test, and (2) to gain experience for such a symposium that would serve as the culmination of the course sequence in the following year. For this pilot symposium, forty undergraduates submitted abstracts by the deadline on September 6. All the abstracts were accepted for a formal presentation or poster. One feature of this symposium was the employment of undergraduates to fill the positions of symposium chair, session chairs, and judges. A reason for this strategy was to increase the number of undergraduates who would gain experience from the symposium. Although the attendance by other undergraduates to this symposium was not as high as desired (fewer than forty), we learned several lessons, ${ }^{15}$ such as relying on poster sessions rather than formal presentations and holding the sessions as close as possible to the College of Engineering, to increase attendance for next year's symposium.

Registration for the research course option began the week after the symposium. To make sure that those who registered would be qualified to secure an undergraduate research position, registration for this course option required instructor approval. Although more than 30 undergraduates applied for the course, the final number of students whom we accepted and who registered for the course was 20 . Table 1 presents statistics on these accepted students. Of particular note were the high GPAs of the students in the course: average of 3.7/4.0. The highest GPA was 4.0, and the lowest was 3.0. Ten of the students had GPAs of 3.9 or above. A couple of students who had GPAs below 3.5 were admitted into the course because their résumés revealed that they would have a good chance of securing a research position. Either those students had research experiences in the past or they showed a high likelihood of securing a summer research position for next summer. 
Table 1. Statistics on the students who registered for the Spring-semester research option.

\begin{tabular}{|l|l|l|}
\hline Characteristic & 2005 Enrollment & 2006 Enrollment \\
\hline Maximum enrollment & 25 students & 25 students \\
\hline Total number registered & 20 students & 16 students \\
\hline Average GPA of students registered & $3.7 / 4.0$ & $3.7 / 4.0$ \\
\hline Gender breakdown & 11 male; 9 female & 10 male; 6 female \\
\hline $\begin{array}{l}\text { Ethnic diversity } \\
\text { 2 African-American; 4 Asian; } \\
1 \text { Hispanic; 1 African }\end{array}$ & 1 Hispanic \\
\hline $\begin{array}{l}\text { Number from groups underrepresented in } \\
\text { engineering }\end{array}$ & $\begin{array}{l}11 \text { students } \\
\end{array}$ \\
\hline
\end{tabular}

Also of note was the diversity of the students in the course. Nine of the students were women, four were Asian, two were African-American, one was Hispanic, and one was African. In addition, five other women expressed interest in the course, but had to withdraw their names because of scheduling conflicts. Of the 20 students registered for the course, 11 were from groups that are underrepresented in engineering. This high number of students from such groups indicated that the research-course sequence has an appeal to students from these groups. In addition to the gender and ethnic diversity of the students in the course, there was diversity in regard to discipline of the students. The following areas of engineering were represented in this course: aerospace engineering, chemical engineering, computer science, electrical and computer engineering, engineering science and mechanics, general engineering, material science and engineering, and mechanical engineering.

For the 2006 course sequence, recruitment began in earnest during the Fall portion of the 2005 course sequence. The recruitment consisted of the same three efforts as in Fall 2004. In the 2005 undergraduate research symposium, more than 40 undergraduates (including all 15 from the Fall segment of the research course option) presented posters, and more than 150 other undergraduates attended. The increase in attendance was due to following the lessons of the pilot symposium in 2004. For the 2005 symposium, three undergraduates, all from the pilot research course option, served as symposium chairs.

From these three recruiting efforts, sixteen students enrolled for the 2006 offering of the research course sequence. As was the case for the 2005 offering, several more applied than were accepted. Overall, the pool of students appears to be talented, as evidenced by the average GPA of 3.7. The pool is diverse, as evidenced by the pool's inclusion of five female students and one Hispanic student. However, the diversity was not as high as the first year. For the next recruitment, we intend to work more closely with the Center for the Enhancement of Engineering Diversity.

Spring Segment of Sequence. During the Spring 2005 and Spring 2006 semesters, we taught the first course (Preparing for Research) in the research sequence to 20 undergraduates $^{14}$ and 16 undergraduates, respectively. The goals of this one-credit segment were as follows: (1) to teach students where to find and how to apply for a funded research experience, (2) to give students a head start on that experience by having them complete a literature review on their research topic, and (3) to teach the students best practices for research. These best practices included ethics in engineering research.

The first main assignment called upon students to apply to at least two research positions through email, web applications, or formal correspondence. To that end, we devoted the first two 
class periods of the course to writing correspondence and resumes. The remaining assignments led to writing a literature review about the topic that the students anticipated that they would research over the summer. Beginning with job correspondence is typical in a traditional technical communication course. , $^{8,10}$

Although all students secured funded offers for research positions, students generally were not sure of their positions until March or April. For that reason, the second main assignment - the literature review - was a challenge for several students. As is customary for technical communication courses, this assignment was anchored in a proposal. For this assignment, students were not obligated to propose the research that they would actually end up doing, but a topic in the general area that they hoped to pursue.

From the writing instructors' viewpoints, the quality of the writing in the job correspondence assignment was higher than the writing of students with similar GPAs in the traditional technical writing courses that they had taught. Students wrote clearly and brought in cogent evidence for their assertions. The reason we attribute for this higher quality was that students had actual positions to which they were applying, and therefore a clearer sense of the audience, purpose, and occasion than most students in a technical communication course. In contrast, the quality of the writing for the proposal was not as high as the proposal writing by students with similar GPAs in a traditional technical communication course. In the traditional course, the students write a proposal about the literature review that they are to perform. In this research course option, though, the scope of the proposal assignment was much more ambitious - the students were proposing actual experiments and computations.

Given that the proposals in the research option were more ambitious and that many students were not sure about what their summer projects would be, students had a difficult time defending the assertions of their proposals. In future offerings of the course sequence, we will have students focus on the proposal's Statement of Problem, which contains the heart of the literature review, and to submit the remaining part of the proposal (the Objectives of Research, Methods of Research, and Schedule for Research) in an outline form. That way, the students will still gain the experience writing a literature review and assembling a proposal.

Presented in Table 2 are responses by the students to selected survey questions at the end of the Spring 2005 course (results from Spring 2006 survey are being withheld until all Spring 2006 data is available). As this survey revealed, the research course influenced the students to apply for research positions that were significantly more competitive than they would have applied for otherwise. That so many students obtained research positions at prestigious institutions (see next section) supports this self-assessment by the students. Also found in this survey was that the research course provided a better understanding for the students of what graduate school would be like as well as made the students more likely to attend graduate school. Both were goals of the research course option.

In addition, from the survey, we learned that the students particularly appreciated the guest presentation on best research practices by a graduate student, even more so than the two guest presentations given by faculty. Our assessment is that students could identify more with the graduate student than with the faculty members. In other words, the undergraduates had a difficult time imagining themselves attaining the success of the faculty member, but could envision themselves reaching the position of the graduate student. Given that, in future 
semesters of this course, we intend to include graduate students and undergraduate researchers who have completed this course as guest presenters and mentors.

Table 2. Responses by students in research course option to selected questions (survey given at end of Spring 2005 course).

Because of this course, I was more inclined to apply for a research position that was highly competitive:

$\begin{array}{llr}\text { Strongly agree } & 8 & 40 \% \\ \text { Agree } & 5 & 25 \% \\ \text { Not sure } & 5 & 25 \% \\ \text { Disagree } & 2 & 10 \% \\ \text { Strongly disagree } & 0 & 0 \%\end{array}$

Because of this course, my application for a research position was significantly more competitive:

$\begin{array}{lrr}\text { Strongly agree } & 4 & 20 \% \\ \text { Agree } & 10 & 50 \% \\ \text { Not sure } & 5 & 25 \% \\ \text { Disagree } & 1 & 5 \% \\ \text { Strongly disagree } & 0 & 0 \%\end{array}$

Because of this course, I have a better understanding of what research in graduate school will be like:

$\begin{array}{lrr}\text { Strongly agree } & 6 & 30 \% \\ \text { Agree } & 13 & 65 \% \\ \text { Not sure } & 0 & 0 \% \\ \text { Disagree } & 1 & 5 \% \\ \text { Strongly disagree } & 0 & 0 \%\end{array}$

Because of this course, I am more inclined to go to graduate school:

$\begin{array}{llr}\text { Strongly agree } & 3 & 15 \% \\ \text { Agree } & 9 & 45 \% \\ \text { Already planned to go } & 4 & 20 \% \\ \text { Disagree } & 1 & 5 \% \\ \text { Strongly disagree } & 0 & 0 \% \\ \text { Already planned to attend } & 3 & 15 \%\end{array}$

Summer Research Experiences. During the Summers of 2005 and 2006, the students in the research course options completed their research experiences. Given in Table 3 are the institutions that hosted those experiences. As shown in the table, more than half of the students obtained positions at institutions other than Virginia Tech. As mentioned, some of the students in the course decided to accept co-op positions with companies rather than to accept research positions. However, these students have the option of obtaining a research experience in a later year and then taking the second portion of the research sequence in the following fall.

Table 3. Locations of funded research experiences for 31 students who had research experiences in 2005 and 2006 calendar years.

Virginia Tech (17 students)

Georgia Tech (2 students)

Bucknell

East Tennessee State University

University of Illinois

University of Karlsruhe

University of Virginia
MIT

Penn State (2 students)

University of South Carolina

Vanderbilt University

Woods Hole Oceanographic Institution

Army Research Laboratory 
At the end of Summer 2005, we surveyed the students to find out about their experiences (results from Summer 2006 survey are being withheld until all Spring 2006 data is available). Presented in Table 4 are results from selected questions of that survey. As shown, students had mixed experiences in their research positions. Some students had experiences in which they did not receive enough guidance or resources from their research advisors. Also, some worked in research areas that are so mature that these students did not have the time to add anything new to the field. In contrast, two others were in new research areas and were able to make contributions in the time that they invested.

Also of note was that several students commented in 2005 that they had to give formal presentations during the summer. The students in 2005 commented that they had received positive or very positive comments on both their writing and their presentations; nonetheless, we devoted one class period in Spring 2006 to presentations so that the students were in a better position to succeed on these presentations.

Also of note in the survey were that six students in 2005 noted the value of the library portion of the spring course. That portion had not been rated as highly in the end-of-course survey. However, three students specifically commented that assembling journal articles about their research topic was their first main task in their summer research experience and that they believed the experience that they had in the spring research course put them in a good position to accomplish this task.

Table 4. Responses from students on selected questions for end-of-summer surveys in 2005 (14 of 18 reporting).

$\begin{array}{llr}\text { Characterize your research experience: } & & \\ \text { Very positive } & 7 & 50 \% \\ \text { Positive } & 7 & 50 \% \\ \text { Neutral } & 0 & 0 \% \\ \text { Negative } & 0 & 0 \% \\ \text { Very negative } & 0 & 0 \%\end{array}$

Which of the following did you encounter during your summer research experience:

$\begin{array}{lrr}\text { Conducting your own research } & 12 & 86 \% \\ \text { Writing a report } & 8 & 50 \% \\ \text { Creating and making a presentation } & 8 & 25 \% \\ \text { Attending a professional conference } & 6 & 5 \%\end{array}$

If you had a writing assignment in your research experience, what type of feedback did you receive on the quality of your writing:

$\begin{array}{lrr}\text { Very positive } & 4 & 29 \% \\ \text { Positive } & 7 & 50 \% \\ \text { Neutral } & 0 & 0 \% \\ \text { Negative } & 0 & 0 \% \\ \text { Very negative } & 0 & 0 \% \\ \text { No feedback given } & 3 & 21 \%\end{array}$

Which of the following aspects of the Spring course was useful in your research position:

Three guest lectures on research $\quad 11 \quad 77 \%$

Class periods on proposal writing $\quad 11 \quad 77 \%$

Class periods on library research $\quad 6 \quad 43 \%$ 
Fall Segment of Sequence. During the Fall 2005 semester, 15 of the original 20 students enrolled for the second course of the sequence: Documenting Research. As mentioned, two of the students had chosen internships rather than summer research positions and delayed their summer research experiences until Summer 2006. In addition, three students decided not to continue to the course's second portion. Of those three, two mechanical engineering students did not do so because they did not need the credit hours for their graduation (they already had enough technical electives). The other student was in a department that did not require technical communication in its curriculum and would not accept the three-credit option as a substitute for any course in its curriculum. This third student simply could not afford to spend the time to take this additional course.

The goals of the fall segment were as follows: (1) to give the students the opportunity to document their summer research experience, (2) to teach the students how to make a professional presentation, and (3) to teach the students how to document a project in a poster and a formal article. As is common in technical communication courses, all of the class periods were devoted to lessons on technical communication. These class periods consisted of critically examining examples of writing and presentations and of performing peer critiques on each other's works.

The first main assignment of the semester called upon students to write an abstract of their summer research for a symposium - the format for the abstract followed the format for abstracts to be submitted to the College's undergraduate research symposium. Because the assignment was due just before the deadline of abstracts for the symposium, the students were in an excellent position to submit their abstracts to the symposium, and all 15 students did. As assessed by the project's writing instructor, the quality of the writing for this assignment was high. We attribute the high quality of writing in this assignment to the fact that students were attuned both to the importance of technical communication in the spring segment of the sequence and to the depth that the students achieved in their research over the summer.

The second main assignment of the semester called upon the students to create a poster of their research projects. Although not a common assignment in a technical communication course, this assignment is a significant mode of communication research both at academic conferences and industry exhibitions. Because every student in the course had submitted an abstract to the undergraduate research symposium and all those abstracts were accepted, these posters were not only submitted in computer file form as an assignment, but also were printed out and displayed at the symposium. As assessed by the project's writing instructor, the quality of the writing for this assignment was very high. Students did an excellent job of presenting much of the research visually and avoiding the common mistake of having too much text on the poster for the audience to read. We attribute the high quality of writing in this assignment both to the importance of technical communication in the spring segment of the sequence and to the depth that the students achieved in their research over the summer.

The third main assignment called upon the students to make a formal presentation of their summer research. This assignment called upon the students to create a set of presentation slides that stood alone as a set of notes. Rather than following the topic-subtopic style of slides that is so common in research presentations, the students were asked to aim higher and create slides that followed an assertion-evidence design. ${ }^{16}$ This design is characterized by a succinct sentence headline supported by visual evidence rather than a bullet list. As assessed by the project's 
writing instructor, the quality of the presenting for this assignment was also very high. Students did an excellent job of presenting the research memorably and persuasively. We attribute the high quality of communication in this assignment both to the importance of technical communication in the spring segment of the sequence and to the depth that the students achieved in their research over the summer. In comparison with students in a traditional technical communication course, students in the research sequence had more time to create strong graphics to communicate their work. Moreover, students had more time to discern what evidence is most persuasive at supporting their assertions. Also, the framing structure of the research course sequence provided opportunities for students to reflect on their research and to contextualize its impact to different audiences, for different purposes, and through different communication modes.

The fourth and final main assignment called upon the students to write a journal article that documented their summer research. Students were allowed to follow the format of any journal or conference proceeding to which they intended to submit their work. If the students did not intend to submit their research for publication, they were asked to follow the format of a journal or conference proceeding in the discipline (for example, the IEEE format for those students pursuing degrees in electrical engineering). As assessed by the project's writing instructor, the quality of the writing on this assignment was mixed. Some students wrote at a level much higher than would typically be achieved by students in a technical communication course. Supporting this assessment is that three of the students had their submissions accepted for professional publications. ${ }^{17-21}$ In two of these cases, the students were the lead author. Another two of the students still have their manuscripts under review.

Although several students wrote at a level that put themselves in a position to become authors or co-authors on professional papers, some students submitted documents that appeared to be hurried. Because this assignment was longer than the other assignments, some students did not budget enough time for the assignment. A lesson learned here was that students should have submitted part of this assignment for review earlier in the semester-perhaps the introduction some time between the abstract and poster assignments and the methods section between the poster and presentation assignment. That way, those students who were not yet experienced in completing a long document would be compelled to spread the writing task out over the entire fall semester.

Another survey was given at the end of this semester. Overall, students felt that the presentation portion of the fall research course was very strong; however, students felt that the writing portion could have been stronger. A lesson from this survey was that the journal article needed to be emphasized more at the beginning of the fall course and perhaps mentioned in the spring course. Having two or three strong examples from this pilot course to serve as examples for future students will let those students know where the "bar rests" in terms of what makes for a strong final article.

\section{Major Challenges to the Course Option}

Surprisingly, the major challenge that occurred during this experiment was not the challenge of whether the students would be able to secure funded research positions for the summer. The principal challenge was the administrative challenge for the different engineering 
departments to have the three-credit research course sequence count either as a substitute for the three-credit technical writing course that some departments required, or as a technical elective in the department's curriculum. Of the four departments that currently require the three-credit technical communication course, one still refuses to count the research option as a substitute. No reason for the decision was stated on paper, but the Department appeared to be reluctant to substitute a technical communication course sequence originating in the College of Engineering for a technical writing course taught in the English Department. Most likely, if the English Department administered the research course option, this department would agree to the substitution.

Of the other eight departments in the College, two of the larger ones-Mechanical Engineering and Industrial Systems Engineering - have agreed that the course option could count as a technical elective. In the end, the research course option can serve as a substitute in the degree plans of about half of the undergraduates in the College. Most of the smaller departments, needing to have students fill their elective courses, simply do not have room in their curricula for this course. For that reason, students from those departments who desire to take this course must do so with the understanding that the course option would be an extra course in their degree plan.

A second challenge is what to do with a student who does not secure a funded research position for the summer. One option is that the student find a research position for course credit over that summer and then document that experience in the fall. Another option is that the student simply performs library research, as is done in the traditional technical communication course. At present, both options are available to students.

\section{Conclusion}

This paper has presented our testing of a research course option as a substitute for the traditional technical communication course. The purpose of this research option is to promote and foster research among those undergraduates. The overall result of this test was that the 2005 pilot research course option has been a success. Students participating in that course sequence secured funded research positions for summer research, and according to the student surveys, the course option deepened those experiences. Another goal was to raise awareness of the benefits of research experience and graduate school. At least 8 students from that pilot year either have begun graduate school or applied to graduate school. Still others in that pilot course have not yet graduated with their baccalaureates.

In 2006, we ran the research course option a second time with another group of students. For this second cycle, we incorporated lessons learned to improve the experience. Also, for the 2007 course recruitment, we have worked more closely with the Virginia Tech Center for the Enhancement of Engineering Diversity to make qualified students from underrepresented groups in engineering more aware of this opportunity.

The next stage is to test this research course option at other universities and with different administrative homes - perhaps within an engineering department or in an English Department. In 2007, Pennsylvania State University has agreed to test a modified version of this sequence in a three-credit option of its required technical writing course, which is taught in the English Department. This tested section will include only engineering students who have had recent 
research experiences. To prepare students for those research experiences, the College of Engineering at Penn State is hosting two workshops for undergraduates during the Spring 2007 semester: one on securing a research position, and the second on preparing for a research position. Because all engineering departments at Penn State require the English Department's technical writing course and because the research option will appear with the same course number on the transcript as the required course from the English Department, all engineering departments at Penn State will accept this research option for course credit to their curricula. For the 2008 calendar year, Clemson University, Georgia Tech, and the University of Illinois at Urbana-Champaign are considering similar research options for their respective technical writing courses.

In the future, should this course sequence prove successful for this level of students (GPA of 3.5 or above), attempts will be made to lower the GPA requirements to determine whether the sequence could serve a larger group of students, some of whom will have a lower academic preparation. Given how many engineering students across the country are currently required to take a technical communication course and how many of those would be qualified to take this course option, and given how successful this experiment has been at enriching the research experiences of undergraduates, other engineering colleges should consider offering such a research course option for their undergraduates.

\section{Acknowledgments}

The authors wish to thank the National Science Foundation for support of this project (NSF Project 0341171).

\section{References}

1. Boyer Commission on Education of Undergraduates in the Research University, 1998 Reinventing Undergraduate Education: A Blueprint for America's Research Universities (New York).

2. National Science Foundation, 1996, New Expectation for Undergraduate Education in Science, Mathematics, Engineering, and Technology (Washington, DC: NSF Directorate for Education and Human Resources), pp.ii, 2, 4, 21, 41, 51, 65 .

3. American Association for the Advancement of Science, 2001, Project 2061 Update (Washington, DC: AAAS).

4. National Research Council, 2003, Evaluating and Improving Undergraduate Teaching in Science, Technology, Engineering, and Mathematics (Washington, DC: National Research Council), p. 116,

5. Ann Q. Gates, Patricia J. Teller, Andrew Bernat, Nelly Delgado, and Connie Kubo Della-Piana, "Expanding Participation in Undergraduate Research Using the Affinity Group Model," 1999, ASEE Journal of Engineering Education, 88 (4): 409.

6. "The Reinvention Center at Stony Brook," 2003, $<$ http://www.sunysb.edu/Reinventioncenter/> (Stony Brook).

7. Laura Reave, 2004, Technical communication instruction in engineering schools, Journal of Business and Technical Communication, 18 (4): 452-490.

8. Michael Alley, 1990, A novel program for teaching writing to engineering undergraduates, Innovations in Mechanical Engineering Curricula for the 1990s (New York: ASME), pp. 1-6. 
9. University of Wisconsin-Madison, 2006, EPD 397: Technical Communication, $<$ http://www.engr.wisc.edu/epd/courses/epd397.html $>$ (Madison, WI).

10. Clemson University, 2006, < http://www.clemson.edu/caah/english/> (Clemson, SC: English Department).

11. National Science Foundation, 2006, Research experiences for undergraduates, $<$ http://www.nsf.gov/crssprgm/reu/reu_search.cfm $>$.

12. Center for the Enhancement of Engineering Diversity, 2004, http://www.eng.vt.edu/academics/ceed_mission.php (Blacksburg, VA: CEED).

13. Writing Guidelines for Engineering and Science Students, 1999, ed. By M. Alley, L. Crowley, J. Donnell, and C. Moore, <http://writing.eng.vt.edu> (Blacks burg, VA: College of Engineering).

14. Michael Alley, Jenny Lo, and Whitney Edmister, 2005, Promoting undergraduate research through a research option in a technical communication course, $<$ http://writing.eng.vt.edu/undergraduate_research.html $>$ (Blacksburg, VA).

15. Michael Alley and Alicia Williams, 2005, A pilot symposium to highlight undergraduate research in engineering, 2005 American Society for Engineering Education Conference \& Exposition, paper 1267 (Portland OR).

16. Michael Alley and Kathryn A. Neeley, 2005, Rethinking the design of presentation slides: a case for sentence headlines and visual evidence, Technical Communication, 52 (4): 417-426.

17. Tracy P. Ng, W. R. Bussone, and S. M. Duma, 2006, The effect of gender and size on linear accelerations of the head observed during daily activities, $43^{\text {rd }}$ International ISA Biomedical Sciences Instrumentation Symposium (April 7-9), accepted.

18. Tracy P. Ng, W. R. Bussone, and S. M. Duma, 2006, Thoracic and lumbar spine accelerations in everyday activities, $43^{\text {rd }}$ International ISA Biomedical Sciences Instrumentation Symposium (April 7-9), accepted.

19. Wei Fan, Tuanzhu Ha, Yan Li, Tammy Ozment-Skelton, David L. Williams, Jim Kelley, I. William Browder, and Chuanfu Li, 2005, Overexpression of TLR2 and TLR4 susceptibility to serum deprivation-induced apoptosis in CHO cells, Journal of Molecular and Cellular Cardiology, doi:10.1016/j.bbrc.2005.09.123 (29 September), pp. 840-848.

20. Katrinia Ramsdell, Madeline Schreiber, Maura Borrego, and Michael Alley, 2006, Integrating a new design of teaching slides with active learning measures in a large class," Proceedings of the 2006 ASEE Annual Conference and Exposition (Chicago, IL: ASEE, 18-21 June), accepted.

21. Michael Alley, Madeline Schreiber, Katrinia Ramsdell, and John Muffo, 2006, How the design of headlines in presentation slides affects audience retention, Technical Communication, 53 (2), pp. 25-34.

22. Elaine Seymour, A-B Hunter, S. Laursen, and T. DeAntoni, 2004, Establishing the benefits of research experiences for undergraduates in the sciences: First findings from a three-year study, Science Education, 88 (4), pp. 493-534.

23. Elaine Seymour, A-B Hunter, S. Laursen, and T. DeAntoni, 2006, Benefits of participating in undergraduate research in science: A comparative analysis of student and faculty perceptions, Science Education, 90 (2). 